\title{
TRABALHO DIGITAL E EMPREGO: a reforma trabalhista e o aprofundamento da precariedade
}

\author{
Jacob Carlos Lima* (http://orcid.org/0000-0001-6475-9575) \\ Maria Aparecida Bridi ** (http://orcid.org/0000-0001-8004-1360)
}

\begin{abstract}
Este artigo analisa as mudanças no trabalho decorrentes das novas tecnologias informacionais e as ocupações oriundas de sua utilização. Entre as ocupações analisadas encontram-se os desenvolvedores de software, os montadores de hardware nas fábricas de equipamentos informáticos, os atendentes de callcenter em serviços terceirizados, como também o trabalho em plataformas digitais. Buscamos responder, ainda que preliminarmente, em que medida a reforma trabalhista estabelecida em 2017 no Brasil favorece a fragmentação ainda maior do trabalho, liberando a terceirização de forma geral, que tem na chamada "uberização" seu formato mais extremo. Concluímos que a precariedade é constituinte desses "novos" trabalhos que surgem num contexto de flexibilidade e inovações tecnológicas, na qual a internet pontifica, mesclando tempo e espaço, embaralhando questões constituintes do próprio valor trabalho, do tempo e espaço, do material e imaterial e do próprio conceito de empresa. Uma das facetas mais contraditórias no chamado capitalismo flexível consiste na transferência do risco da atividade econômica para os trabalhadores.

Palavras-chave: Trabalhadores digitais. Tecnologias da Informação e Comunicação. Uberização. Reforma trabalhista. Tecnoliberalismo.
\end{abstract}

\section{INTRODUÇÃO}

A informatização crescente de todas as atividades econômicas, em âmbito global, tem contribuído para aumentar, mesmo nos países em desenvolvimento como o Brasil, as chamadas atividades criativas e (ou) cognitivas. Uma economia que depende cada vez mais de descobrir, processar e aplicar informações on-line exige trabalhadores mais escolarizados, com domínio da linguagem informacional e da lógica numérica que caracteriza essas atividades (Castells, 2003, p. 19). A chamada "inclusão digital" constitui-se numa forma de acesso a esse novo tipo de sociedade.

Ao lado das competências vinculadas à formação escolar e à familiaridade com as novas tecnologias, exige-se dos trabalhadores, cada vez mais, que sejam empreendedores, móveis e flexíveis, e que seus conhecimentos sejam pro-

* Universidade Federal de São Carlos. Departamento de Sociologia.

Rodovia Washington Luís, Km 235. São Carlos - São Paulo - Brasil. calimajb@gmail.com

** Universidade Federal do Paraná. Departamento de Sociologia.

Rua General Carneiro, 460 - $9^{\circ}$ andar. Cep: 80.60-150. Curitiba - Paraná - Brasil. macbridi@gmail.com gressivos e mutáveis. Exige-se, assim, uma formação com atualização permanente, de caráter inovador, num quadro de relações de trabalho cada vez mais individualizadas, em diversos tipos de contrato, ou mesmo sem contrato algum, apenas como prestação de serviços.

Esse novo mundo do trabalho é marcado por uma cultura tecnocrática cujo espaço virtual é a internet. Uma cultura anárquica, hacker, subversiva, comunitária e colaborativa, que, para alguns teóricos do capitalismo cognitivo, prega uma liberdade que representaria um potencial emancipatório, no qual os trabalhadores recuperariam o controle de seu trabalho e de seus destinos. A essa cultura soma-se a cultura empresarial-empreendedora, que incorpora a ideologia da liberdade possibilitada pela internet. No discurso, defende-se a construção aberta e de livre modificação de softwares, o que, a partir de um saber compartilhado, democratizaria seu acesso e as atividades que propiciam. Dessa forma, suas aplicações transbordariam para todos os níveis da vida econômica, social e política.

Esse saber compartilhado, entretanto, é relativo, considerando que parte do software 
construído coletivamente termina sendo apropriado privadamente por empresas que fecham os códigos, controlam linguagens e algoritmos (Castells, 2003). Assim, ao lado do grande otimismo que acompanhou o surgimento da chamada economia do compartilhamento, assistimos à oligopolização desse compartilhamento por empresas globais. Segundo Nascimento (2016, p. 224), "as grandes corporações financeiras (Amazon, Netflix, Apple, Microsoft etc.), as redes sociais digitais (Facebook, Twitter, Tumblr, Instagram etc.) e os gerenciadores de busca (Google, Bing etc.), todos eles dispõem atualmente de uma produção contínua e massiva de dados acerca do tipo e da amplitude de nossas interações sociais”, colocando em questão nossa privacidade e a tendência a uma sociedade cada vez mais controlada por esses monopólios. São os chamados big datas.

Para Sadin (2016, p.21), a lógica informacional contemporânea se cruza e se confunde com a lógica própria do liberalismo, que aspira, de forma permanente, à conquista de novos mercados, o que transforma o liberalismo num tecnoliberalismo que realiza sua aspiração de não ter entraves ou limites à sua expansão em todos os domínios da vida. A economia digital aspira a fazer de todos os gestos, alentos, relações sociais e subjetividades uma $\stackrel{2}{\sigma}$ possibilidade de lucro.

A informatização e o papel das infraestruturas computacionais têm impactado profundamente na vida social: na educação, no transporte, na vida familiar, na vida afetiva, no ativismo político. Cada vez mais, nosso cotidiano é afetado pelos dispositivos informacionais que capturam dados, e possibilitam novas formas de consumo, criando moralidades, fazendo e desfazendo reputações, monitorando nosso comportamento através dos smartfones e aplicativos diversos nas redes sociais, como no Twitter, no Facebook e em outras. Segundo Miskolci, estaríamos frente à consolidação de um processo sociotécnico em que

[...] as relações sociais passam a ser crescentemen- te criadas, mantidas ou aprofundadas por meio do uso de equipamentos para comunicação em rede. Em outras palavras, na sociedade digital passamos a viver em um contínuo on-off line, no qual - conectados em rede por meio de plataformas - consumimos, mas também criamos e compartilhamos conteúdos (Miskolci, 2016, p. 277).

Nesse contexto, emerge uma diversidade de empresas de novo tipo, marcadas pela flexibilidade e atuação em rede, como é o caso de empresas prestadoras de serviços de tecnologia da informação, de multinacionais de teleatendimento e que não se enquadram, por exemplo, no conceito jurídico de empresa em seu sentido clássico. São empresas que conectam outras "empresas e pessoas através de computadores e outros meios de comunicação, possibilitando a formação e a organização de redes"; produzem "uma mercadoria imaterial”, isto é, "o relacionamento entre um cliente e o seu cliente/consumidor ou potencial consumidor"; produzem mercadorias que não apresentam "uma materialidade concreta, uma tangibilidade, visto que produzem uma relação", E é essa "relação entre cliente e empresa, que é a sua expertise" (Bridi; Machado; Portela, 2017, p. 3).

Essa situação traz novos desafios para a sociologia, não apenas de cunho metodológico, vinculados à natureza e à profusão de dados (como os big datas controlados por oligopólios empresariais), às formas de utilização e validação dos dados obtidos, mas, principalmente, pelas transformações que essas tecnologias trazem para a vida social e suas consequências em termos econômicos, sociais, políticos e culturais. Não é nova a relação da sociologia com dados computacionais. O que muda, agora, é sua dimensão, as formas de acesso e como analisá-las a partir das novas plataformas digitais.

Desse modo, a partir de pesquisas empíricas realizadas pelos autores e de reflexões teórico-metodológicas, analisamos, neste artigo, as transformações no trabalho a partir da utilização das tecnologias digitais, as chamadas Tecnologias de Informação e Comunicação (TICs), e as ocupações emergentes oriundas, 
direta ou indiretamente, de sua utilização. Entre essas ocupações, privilegiamos as mais representativas dessas mudanças: desenvolvedores de software, montadores de hardware nas fábricas de equipamentos informáticos, atendentes de call center em serviços terceirizados, bem como, o trabalho em plataformas digitais, do qual o "modelo UBER" é ilustrativo. Nesse caso, por exemplo, pesa a controvérsia na qual a empresa se enquadra, como de tecnologia, enquanto, de fato, o que ela realiza, do ponto de vista do trabalho, é o transporte de passageiros e a entrega de encomendas.

Ao analisar essas atividades, indagamos em que medida a reforma trabalhista, realizada em 2017 no Brasil, favorece o que podemos chamar de "uberização" do trabalho, cujo conceito pode configurar tanto a relação de trabalho de motoristas da UBER quanto a dos desenvolvedores de software, que se encontram na condição de pessoas jurídicas. Ao analisar as formas de contratação nessas atividades, concluímos que a precariedade é constituinte desses "novos" trabalhos que surgem num contexto de flexibilidade e inovações tecnológicas, no qual a internet pontifica, mesclando tempo e espaço, embaralhando questões constituintes do próprio valor trabalho, do tempo e do espaço, do material e imaterial e do próprio conceito de empresa. Nesse contexto de relações contratuais frágeis, uma das facetas mais contraditórias, no chamado capitalismo flexível, consiste na transferência para os trabalhadores de todo e qualquer ônus da flexibilidade e do risco.

\section{TECNOLIBERALISMO E OS TRA- BALHADORES DA ERA DIGITAL}

A disseminação do uso de computadores, da internet e de outras ferramentas tecnológicas informacionais, popularizadas a partir das últimas décadas do século XX, possibilitou novos negócios, novos tipos de empresas, bem como novas categorias profissionais - os trabalhadores "informacionais", "digitais”, "infor- matas", "profissionais de TI", "infoproletários" entre outras, nos diferentes ramos econômicos. Na esteira do que podemos nomear de "indústria informacional", ou "indústria digital", o trabalho e os trabalhadores apresentam-se organizados ou inseridos na dinâmica de um capitalismo flexível, com trabalhos flexíveis e diferentes e flexíveis modalidades de contratação e de relações salariais (Lima; Bridi, 2018). O trabalho - organizado nas várias modalidades de empresas, de diferentes portes, natureza e configurações - desafia os estudos sociológicos, pois se inaugura uma economia que se organiza e se potencializa fortemente por meio de softwares e aplicativos. ${ }^{1}$ Daí decorrem transformações com enormes desdobramentos sociais, culturais e políticos.

Para Nascimento (2016, p. 218), “a cultura, as relações sociais e as instituições se alteraram profundamente, na medida em que novas formas de comunicação dependentes das tecnologias digitais adquiriram um uso generalizado [...] e impactaram o modo como fazemos ciência, reverberando, também, na disciplina da sociologia”. Longe de qualquer determinismo tecnológico, vale ressaltar que essas tecnologias se desenvolvem e se expandem num contexto de transformações capitalistas, na passagem do que a escola de regulação francesa chama de "acumulação flexível" - flexibilidade de mercados, da produção, da utilização da força de trabalho, do consumo. Sob que condições se dá a realização desses trabalhos, no entanto, depende de um conjunto de fatores encetados no âmbito da política, das decisões dos agentes públicos dos três poderes (Executivo, Legislativo e Judiciário), que definem o sistema de regulação desses trabalhos, se mais

1 Segundo os especialistas em tecnologia da informação, um software se distingue de um aplicativo. Enquanto o software exige uma máquina complexa (computador, por exemplo), fazendo-a operar, sendo, portanto, sistemas operacionais mais robustos, um aplicativo pode ser desenvolvido e disponibilizado em lojas de aplicativos como Play Store, Android Play, Microsoft Marketplace, dentro de um software instalado com finalidades específicas, compras de determinados produtos, informação, música etc. Como exemplo, citamos o celular (máquina) que tem um software (programa) instalado, que é o que o faz funcionar e que, por sua vez, permite receber aplicativos de diversas ordens. 
ou se menos protegidos pela legislação, e da própria força da classe trabalhadora. O Brasil, por exemplo, que, historicamente, apresenta formas de contratação de trabalho flexíveis (Krein, 2001), a partir da Reforma Trabalhista de 2017, tem essa flexibilidade potencializada, visto que a nova legislação oferece um mosaico de possibilidades de trabalhos desregulados.

As tecnologias informacionais respondem a essas novas configurações possibilitando uma diversidade de arranjos de empresas, por exemplo. Nesse contexto, discute-se uma "sociologia digital", não apenas em termos metodológicos - como utilizar dados e instrumentos de pesquisa -, mas de uma busca de mobilizar o referencial teórico da disciplina para entender os desafios postos num momento no qual as relações sociais são fortemente mediadas e moldadas pelos dispositivos e pelas mídias digitais. Às preocupações centrais da sociologia - individualidade, identidade, desigualdades, instituições, estruturas sociais - somam-se as transformações de cunho tecnológico com a mediação da conectividade digital que, mesmo sem substituir as relações sociais presenciais, intensificam essas relações por ampliá-las, aumentando a interação (Lupton, 2015; Miskolci, 2016). O crescimento das plataformas de mídias sociais, mobile applicaItions, e novas formas de dados e infraestrutui . ras inteligentes, inflexionam modos, práticas $\stackrel{\circ}{*}$ de vida em diferentes direções. Em outros termos, a vida passa a ser organizada em algoritmos (Marres, 2017).

Embora ainda tateando, como disciplina ou subárea da sociologia, esse enfoque busca juntar os desafios colocados pelas tecnologias midiáticas em suas relações com os indivíduos, impactando suas relações sociais e, em grande medida, transformando-as a partir da interação propiciada por dispositivos digitais. Essa interação, ao mesmo tempo que propicia a reprodução de aparatos de dominação e controle, fornece ferramentas para resistências, como podemos observar no ativismo político dos últimos anos, em manifestações convocadas pela internet, boicotes etc., embora possamos questionar fortemente seu caráter emancipatório.

Sociedades digitais são marcadas por complexas interações entre vida social e conhecimento, entre pesquisa social e ação social. Hoje, as transformações digitais invocam debates importantes sobre o passado da sociologia e sobre o papel das ideias e tecnologias na vida social. O "digital” figura como importante fenômeno societal que requer investigação. Como fonte de dados, os big data (conjunto de dados armazenados em plataformas digitais) se constituem em artefatos socioculturais que "não possuem uma existência autonomizada em relação ao mundo social, pois é na referência ao comportamento humano e às dinâmicas da vida em sociedade que eles precisam e devem ser pensados" (Nascimento, 2016, p. 225).

Não nos deteremos aqui sobre os equipamentos e dispositivos que marcam essas novas formas de interação, mas sobre a interação em si, sobre as novas expressões do trabalho inflexionadas pelas tecnologias digitais, especificamente, sobre como se alteram as formas de trabalho, a organização e as relações, considerando que a imaterialidade do digital não se dissolve no ciberespaço. Os softwares e os dados mantêm-se vinculados às materialidades representadas por equipamentos e infraestruturas de computadores e redes fisicamente compostas (Flecker, 2016, p. 3), com formas de produção em massa, fábricas, empresas, divisão do trabalho, formação e qualificação dos trabalhadores, organização coletiva, enfim, um conjunto de situações que merecem ser investigadas.

Temos como referência a subordinação e a exploração inerentes às relações entre capital e trabalho, supondo que elas caracterizam as atividades informacionais, mas que exigem um avanço na análise para evitar uma camisa de força conceitual que desconsidera as especificidades dos "novos trabalhos" dificultando uma maior compreensão das mudanças em curso.

Para autores como Rifkin (2016), as relações (entre capital e trabalho) estariam ameaçadas pela economia compartilhada e pela 
generalização da utilização das tecnologias informacionais e da internet nos produtos, nos serviços e na vida social como um todo. A chamada quarta revolução industrial, a internet das coisas - a conexão de dispositivos eletrônicos utilizados no dia a dia junto à rede mundial de computadores -, otimizando sua utilização, levaria a produção, na sociedade, a um custo marginal zero, ${ }^{2}$ por um lado, e, numa constatação absolutamente pessimista, à casualização $^{3}$ do trabalho e dos direitos sociais, generalizando-se uma situação de precariedade.

Há várias facetas do trabalho nesse contexto de um "capitalismo informacional" e "flexível". Se, de um lado, tem-se o conhecimento como um dos fatores centrais, como anunciaram os defensores da tese de que transitamos para uma "sociedade da informação", ${ }_{4}$ de outro, há novas atividades e novas categorias profissionais, como os trabalhadores de software, o que inclui desenvolvedores, analistas, designers e outros profissionais representativos de uma nova dinâmica de trabalho, marcados pela imaterialidade de sua atividade e dos conteúdos necessários para sua efetivação, além da marca simbólica representada pela utilização de algoritmos. Esses seriam os trabalhadores do conhecimento (na perspectiva das tecnologias digitais). Do outro lado, dessa mesma "indústria" ou "serviço", cujos limites são imprecisos e colocam em questão essa separação, há os trabalhadores proletarizados por essas mesmas tecnologias, como os trabalhadores de hardware e de call centers, e os trabalhadores de plataformas digitais que alteram as relações de trabalho vinculando-se a aplicativos e mascarando a subordinação entre capital e trabalho.

\footnotetext{
${ }^{2}$ Para Paulani (2016), o fundamento do preço das mercadorias "imateriais" permanece no caráter da propriedade privada, no qual a indústria de software é paradigmática.

${ }^{3} \mathrm{O}$ termo casualização do trabalho (casualization of work) refere-se ao trabalho não permanente, parcial, temporário, free lancer, temporário, autônomo. Para uma discussão da casualização e da recasualização do trabalho no capitalismo, ver Broad (2000).

"Sobre a "sociedade da informação" e correntes do pós-industrialismo, ver Lima e Bridi (2018) e Kumar (1997).
}

Eles representam uma tendência, já apontada por Braverman (1974) na década de 1970, à formação crescente de um grupo de trabalhadores altamente qualificados, com contratos estáveis e bons salários, secundados por uma maioria desqualificada, força de trabalho barata, abundante e disponível para um mercado cada vez mais preocupado com a redução de custos. O que muda agora, com a globalização desses mercados, é a precarização geral de qualificados e desqualificados, visto que cresce o número de trabalhadores também qualificados, mas com contratos parciais ou "contratos verbais”, sem formalização alguma, desterritorializados, desvinculados de direitos sociais e de qualquer proteção no trabalho. Um engenheiro indiano de software ganha dez vezes menos que seu colega norte-americano e trabalha, em seu país natal, numa empresa que pode ser nacional, mas terceirizada em cadeias globais. ${ }^{5}$

Embora distintas em relação ao conhecimento exigido, as novas ocupações digitais ora se aproximam, ora se distanciam de outros grupos de trabalhadores em termos de jornadas, padronização de trabalho, contratos e condições de trabalho. Juntá-las nos permite tecer considerações sobre tendências atuais no mundo do trabalho, tendo em vista a inserção das tecnologias digitais em todas as atividades econômicas.

\section{A PRODUÇÃO DE SOFTWARE E SEUS DESENVOLVEDORES}

A indústria de informática, nas últimas décadas, cresceu globalmente, produzindo softwares - programas, aplicativos, jogos - que são utilizados e aplicados em todos os setores produtivos e de serviços, e hardwares, que são as máquinas que rodam os programas, como os

${ }^{5}$ Segundo o DIEESE (2003, p. 20) utilizando dados publicados pelo CPSR (Computer Professionals for Social Responsability - Profissionais de Computação com Responsabilidade Social), "os trabalhadores americanos da área de TI recebem cerca de US\$ 80 mil por ano, enquanto os indianos recebem US\$ 8.500,00. Os que trabalham sob o regime de visto $\mathrm{H} 1 \mathrm{~B}$, nos Estados Unidos, recebem cerca US\$ 39 mil por ano". 
computadores de diversos tipos e cuja funcionalidade se vincula aos softwares, tendo sua utilidade determinada pela função que lhe é atribuída e que o software viabiliza. Além disso, existem ainda os telefones celulares, Ipads, Ipeds, Ipods e outros, que dependem de softwares e da internet para funcionar.

As tecnologias informacionais dinamizaram setores produtivos, criando novos, encerrando outros que se tornaram obsoletos e revolucionando a sociedade a partir de uma lógica flexível de produção, de distribuição e de consumo. Tudo isso ocorre ao lado da indústria eletroeletrônica, da nanotecnologia e da revolução nos transportes, que tornaram o mundo menor. Esse contexto foi chamado de várias formas sociedade informacional, capitalismo cognitivo, sociedade em rede, pós-moderna e outras -, que compreendem um conjunto de transformações tecnológicas, políticas, econômicas e culturais dos últimos 50 anos. Conhecimento e informação tornam-se fatores de produção e valorização do capital (Lima, 2017).

A produção de software se distingue pela imaterialidade de sua produção final, assim como pela forma como é realizada. O software está contido em diferentes tipos de suporte físico, com o objetivo de possibilitar a utilização de equipamentos de processamento eletrônico

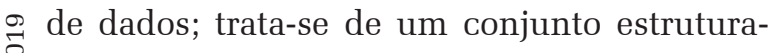
do de instruções, procedimentos, programas, regras e documentação, interpretadas por um computador, através de linguagens de programação (abertas ou fechadas) na realização de determinadas tarefas.

A produção de software pressupõe ainda a codificação do conhecimento e de informações, sendo que seus inputs e outputs são imai teriais. Dependendo da forma como se proveem esses outputs, eles podem ser considerados produtos ou serviços, embora a distinção nem sempre seja muito clara. Como produtos, são vendidos por meio de licenças e patentes para uso empresarial ou individual; ou na forma de soluções empresariais por encomenda, o que exige alguma personalização ou adaptação para sua utilização; ou ainda como produtos acabados para mercados mais amplos. Mesmo sendo um produto, a empresa desenvolvedora, em geral, acopla serviços, como atualização das versões, suporte técnico e manutenção. Como serviços, além do acompanhamento, requerem atividades como desenho e desenvolvimento de soluções por encomenda, implementação e adaptação de serviços de terceiros, consultoria, capacitação, instalação e manutenção dos softwares. É uma atividade marcada por grande insegurança quanto à eficiência, operabilidade, confiança no sistema e falhas, devido a incertezas e erros (bugs) que comprometem seu funcionamento adequado (Gutiérrez, 2011, p.12-14) e exigem do trabalhador a capacidade de resolução de problemas.

Esse trabalho se caracteriza por um maior controle do trabalhador sobre a atividade de elaboração do produto, e a formação é possibilitada pela própria utilização de softwares na rede, assim como por contratos de trabalho variados. Essa flexibilidade "genética", possibilitada pela tecnologia informacional, particulariza esse trabalho, em comparação com outros ligados à materialidade da produção e do consumo.

No processo de trabalho, o trabalhador de software não apenas participa do desenho dos algoritmos (signos), mas possui certo controle do saber como e por que esses signos são construídos a partir das linguagens de programação. O processo de trabalho vincula-se à produção de signos, os algoritmos, a partir de outros símbolos, as linguagens de programação. Esse procedimento supõe um intercâmbio de informação e conhecimentos entre aqueles que participam do processo (Gutierrez, 2011, p. 43).

Geralmente, os trabalhadores ou profissionais do setor entram em tarefas de suporte ou acompanhamento dos produtos, o que, por sua vez, exige que eles os conheçam. As funções de analista e programador são centrais na elaboração do produto, e o gerente de vendas garante a relação com o mercado e as possibilidades de atendimento do cliente. 
O cliente é ator fundamental do processo, pois especifica sua necessidade, o que possibilita elaborar tecnicamente o projeto. A projetificação é uma característica da área. O fim do projeto pressupõe seu acompanhamento e manutenção. Novos projetos garantem a empresa e o emprego (Bridi; Braunert, 2015; Lima; Bridi, 2018).

As grandes empresas buscam a padronização das tarefas, mas isso não é fácil, devido ao erro constante e à necessidade de o trabalhador resolver problemas. De qualquer forma, nas grandes empresas, isso é visível, sobretudo na etapa da programação, pois o programador, paulatinamente, tem se transformado naquele que apenas realiza a codificação do projeto a ser desenvolvido por outros. Nas pequenas, nem sempre as fronteiras entre as funções são muito precisas. Concepção e execução, nessas empresas, podem ser uma só coisa, o que impacta na organização do trabalho, com o aumento de risco e a incorporação dos erros e das falhas como parte do processo, como já foi assinalado (Tainturier; Duez, 2017).

A terceirização da produção é uma constante, com a utilização de consultores como pessoas jurídicas (PJs) e trabalhadores autônomos no desenvolvimento de tarefas e projetos específicos. Ao mesmo tempo, certo caráter colaborativo persiste no auxílio à resolução de questões no processo de produção, no qual a rede tem um papel central, e os trabalhadores trocam informações, incorporando trabalho não pago.

Longe da idealização inicial dos gênios de garagem, que marcaram o início da produção no Sillicon Valley, com seus líderes encarnando a versão extrema da audácia e da inventividade empreendedora, e mesmo contracultural (Sadin, 2016), a área de software está cada vez mais especializada, com trabalhadores cada vez mais escolarizados. Isso não significa uma rígida formação escolar na área de informática, como técnicos ou profissionais de ensino superior. É comum a presença de profissionais de outras áreas com domínio téc- nico na utilização de programas e linguagens.

No Brasil, grandes empresas multinacionais e estatais concentram $50 \%$ do trabalho no setor de software. Essas empresas representam $4 \%$ do setor no Brasil, o qual é majoritariamente formado por micro, pequenas e médias empresas distribuídas por todo o país, as quais produzem software por encomenda e (ou) embarcado $^{6}$ (SOFTEX, 2012), empregando em torno de um milhão de trabalhadores e sendo responsáveis por mais de $50 \%$ da força de trabalho empregada (Lima; Oliveira, 2017).

Estudos sobre o Vale do Silício, nos EUA, indicam forte individualização dos contratos de trabalho e a socialização do trabalho (Benner, 2005). Essa individualização vem somada à prevalência do autoemprego, empregos temporários vinculados a projetos, grande rotatividade de trabalhadores entre as empresas e fragilidade sindical.

No Brasil, embora essas características estejam fortemente presentes, o que predomina, nas grandes empresas privadas ou estatais, são os contratos formais de emprego (70\%), decorrentes de um conjunto de fatores surgidos na última década, entre os quais o forte aquecimento do mercado no setor. A demanda de empresas públicas e organismos governamentais, com exigências de editais, além de empresas privadas, explica a formalização das atividades empresariais e dos contratos dos trabalhadores (Lima; Oliveira, 2017). Mesmo assim, isso é uma ponta visível do mercado de trabalho. Bridi e Braunert (2015), por exemplo, identificaram um movimento de crescente pejotização de trabalhadores atuando em diversas modalidades contratuais (MEI, Cooperativas, CLT-Flex), com a ampliação da condição como pessoas jurídicas. A terceirização generalizada no setor nem sempre aparece em termos de contratos formais, e parte significativa desses contratos estão fora das estatísticas oficiais.

As jornadas de trabalho, embora sejam majoritariamente regulares, constituem um as-

${ }^{6}$ Que integra outros produtos, como, por exemplo, em automóveis, aparelhos domésticos, maquinaria, etc. 
pecto nebuloso nessa atividade, dada a projetificação que caracteriza o setor e a necessidade de cumprir prazos estabelecidos. A internet e a existência de dispositivos móveis permitem a extensão das jornadas para além do contratado. A resolução de problemas, o celular e a urgência de atendimento a clientes borram a fronteira do tempo de trabalho e de não trabalho, embaralhando vida pessoal e vida profissional, situação comum a atividades não propriamente "digitais", como as de professores, pesquisadores e outros que utilizam essas tecnologias e, cada vez mais, têm suas atividades determinadas pela utilização de dispositivos informacionais.

Percebe-se que a relação entre tecnologia e gênero, no setor que se caracterizaria pelo trabalho "criativo", é fundamentalmente masculina. Segundo dados da SOFTEX (2012), apenas $12 \%$ dos trabalhadores do setor são mulheres. E geralmente isso é justificado pela tendência, "naturalmente" masculina, de se interessar por tecnologias. Mesmo com esse número reduzido, percebe-se que essas mulheres são maioria em trabalhos home office, fora das empresas, procedimento comum nesse tipo de negócio, justificado pela necessidade de maior proximidade com a família (Castro, 2016; Oliveira, 2017). O mesmo ocorre com contratos de PJ e de prestação de serviços autônomos.

Como foi dito acima, a maioria dos contratos em empresas de software, no Brasil, são regulares, regidos pela CLT (SOFTEX, 2012), o que destoa, por exemplo, da situação na Grã-Bretanha, nos EUA e na Argentina, aproximando-se da Alemanha e países nórdicos (Mayer-Ahuja; Wolf, 2007; Miguez; Lima, 2016). O caso brasileiro pode ser explicado pela expansão do setor nas últimas décadas, pelo forte aquecimento do mercado, mas também pela intensa presença do Estado na compra de serviços, o que, dentre as regras de licitação, exige uma regularização das relações de trabalho. Essa situação, contudo, pode se alterar significativamente tanto pela reforma trabalhista aprovada em 2017, quanto pela Lei de Terceirização, que amplia a possibilidade de terceirização para as atividades-fim. Esse, contudo, é um campo aberto para a investigação sociológica, visto que, embora já existam algumas expressões dessas mudanças, o campo ainda se encontra em situação de disputa jurídica.

\section{O PROLETARIADO DO HARDWA- RE E OS CALL CENTERS}

Ao lado dessa "aristocracia profissional" dos trabalhadores do conhecimento, representados pelos desenvolvedores de software, existe o que podemos associar a um proletariado informacional, contratado por empresas de fabricação de hardware, a maior parte asiáticas, mas que possuem plantas em vários países em desenvolvimento, representadas, entre outras, pela Foxconn (Sadin, 2016). São montadoras de equipamentos que possuem condições e cadências de trabalho tipicamente tayloristas, com diferentes graus de automação, sendo algumas delas denunciadas por péssimas condições sanitárias e por serem poluidoras em diversos países, além de, a depender dos regimes regulatórios do trabalho vigentes, funcionarem com jornadas e ritmos extenuantes, expondo os trabalhadores a inalações tóxicas que comprometem a saúde.

No Brasil, essas montadoras pouco se diferenciam de outras do setor de montagem de eletroeletrônicos. Com condições de trabalho melhores do que as descritas acima, elas se submetem às normas vigentes no país, assim como à vigilância sindical sobre o pagamento do piso salarial da categoria. Em uma dessas unidades, na região de Sorocaba, os trabalhadores ficavam em pé numa linha de montagem de computadores - desktops e laptops -, onde montavam os equipamentos com peças importadas, em sua maioria da China, em que pese haver regras sobre o índice de nacionalização das peças utilizadas (Lima, 2017). Em outra fábrica, produtora nacional de computadores, localizada em Curitiba desde sua criação em 1989 até $2015,{ }^{7}$ apresenta-se um processo

${ }^{7}$ Essa empresa finalizou sua transferência para a Zona Franca de Manaus em 2016, com o objetivo de redução de custos. 
produtivo muito semelhante ao de outros setores industriais tradicionais, como a de componentes eletrônicos, automóveis, rádios etc., com a maioria dos trabalhadores operacionais do sexo feminino recebendo baixos salários e apresentando grande rotatividade (média, na empresa, de dois anos). Do ponto de vista da produção de hardware, pouco há de novo no horizonte do trabalho nesse segmento, na medida em que os trabalhadores que operam a montagem de computadores e componentes informáticos "com nível de escolaridade mais baixo (nível médio)" produzem "em moldes fordistas/tayloristas, ainda que nuançados pela produção flexível e com ganhos modestos" (Bridi, 2014, p. 301). No país, essa categoria de trabalhadores compõe o operariado fabril regular, escolarizado, formalizado, com registro de trabalho e regido pelas normas da CLT.

São os call centers que figuram entre os maiores empregadores no Brasil, os representantes de um novo operariado não industrial, os infoproletários (Antunes; Braga, 2009), tendo ultrapassado as fábricas em termos de número de trabalhadores por unidade. De um total de 135 empresas em 2017, cerca de 49 delas ocupavam mais de 1000 trabalhadores cada, sendo que delas, nove ocupavam entre 10.000 e 20.000 trabalhadores, três entre 24.000 e 32.000 , e duas entre 86.000 e 94.000 , distribuídos por todo o país.

Quadro I - Maiores empresas de call centers do Brasil por número de trabalhadores - 2017

\begin{tabular}{|l|c|c|}
\hline Posição & Empresa & Trabalhadores \\
\hline 1a. & Atento & 96.000 \\
\hline 2a. & Contax & 84.508 \\
\hline 3a. & Almaviva do Brasil & 32.062 \\
\hline 4a. & AeC & 32.000 \\
\hline 5a. & Tivit & 24.000 \\
\hline 6a. & Teleperformance & 18.000 \\
\hline 7a. & Call Contact Center & 14.152 \\
\hline 8a. & Algar Tech & 14.000 \\
\hline 9a. & TMKT & 13.763 \\
\hline 10a. & BTCC Conexão Cliente & 13.407 \\
\hline
\end{tabular}

Fonte: http://ranking.callcenter.inf.br/monteseuranking/?r=func.
Os call centers podem ou não integrar "fábricas de software". No geral, são empresas nacionais ou multinacionais que trabalham terceirizadas para outras empresas na prestação de serviços como cobranças bancárias, atendimento a clientes e vendas de produtos. Quando vinculados às fábricas de softwares, podem exigir um trabalhador mais qualificado, com habilidades linguísticas para atender a clientes globais. Mas, no geral, limitam-se à prestação de serviços, estando distribuídas por todo o país. São empregos formais, com grande rotatividade, dadas as condições estressantes de um trabalho controlado por várias formas digitais: o computador estabelecendo o ritmo e as características de como os atendimentos devem ser feitos; o controle digital desses atendimentos; além dos controles das empresas primeiras e dos supervisores físicos no espaço de trabalho. Nesse caso, não existe necessariamente uma precarização contratual, mas do processo de trabalho. Em 2012, o número de trabalhadores empregados nesses call centers era de 1,2 milhão. Cerca de 69,03\% eram mulheres, cerca de $50 \%$ do total $(49,45 \%)$ possuía até 25 anos e $80,38 \%$ tinha o ensino médio completo. $^{8}$

A Atento, por exemplo, uma multinacional de novo tipo que nasceu e se estabeleceu no Brasil em 1990, no contexto da privatização do setor de telecomunicações, "é uma empresa fornecedora global, provedora de gestão de relacionamento com clientes e serviços na América Latina" e que presta serviços a vários e diferentes setores, ${ }^{9}$ "para os quais oferece uma infinidade de soluções: vendas, atendimento ao cliente, suporte técnico, gestão da reclamação, cobrança, back office, gestão de crédito, trade marketing, entre outros" (Bridi; Machado; Portela, 2017, p. 14).

${ }^{8}$ Cf.: <http://portalcallcenter.com.br/index.php/2014-0526-18-14-11/ 4558-estudos-atualizam-dados-sobre-o-mercado-de-trabalho-do-call-center > . Acesso em: 17.07.2017.

${ }^{9}$ São eles: telecomunicações; serviços bancários, financeiros e seguros; saúde; tecnologia; varejo e-commerce; bens de consumo; governo; hotelaria e turismo; serviços públicos; comunicação e mídia; transporte e logística; automotivo e farmacêutico. 
Tabela 1 - Informações globais da empresa Atento: número de empregados, tipo de contrato e percentual de mulheres - totais da multinacional e em diversos anos

\begin{tabular}{c|c|c|c}
\hline Ano & $\begin{array}{c}\text { Número de } \\
\text { empregados }\end{array}$ & $\begin{array}{c}\text { Contratados } \\
\text { por tempo } \\
\text { indeterminado }\end{array}$ & $\begin{array}{c}\text { Percentual } \\
\text { de } \\
\text { mulheres }\end{array}$ \\
\hline 2011 & $156.734 \mathrm{mil}$ & $69,9 \%$ & $69,1 \%$ \\
\hline 2012 & $153.638 \mathrm{mil}$ & $70,84 \%$ & $60 \%$ \\
\hline 2013 & $155 \mathrm{mil}$ & - & $75 \%$ \\
\hline 2014 & $159 \mathrm{mil}$ & $75 \%$ & $67 \%$ \\
\hline
\end{tabular}

Fonte: Relatórios de Responsabilidade Social da Atento - (totais diversos anos e centrais no mundo). Elaboração: Bridi, Machado e Portela (2017).

Como se depreende desses dados, predomina a mão de obra jovem, feminina, formal, com uma franja de cerca de $30 \%$ com outras modalidades contratuais. A empresa é organizada internacionalmente para prestar um tipo de serviço, que é a atividade de atendimento entre as empresas e seus consumidores. Sua expertise é a relação entre a empresa e o consumidor. Em uma breve pesquisa jurisprudencial no Brasil sobre essa empresa, Bridi, Machado e Portela verificaram a existência de um número significativo de ações trabalhistas pedindo o reconhecimento de vínculo empregatício entre empregados da Atento e a tomadora de serviços, com a alegação da ilicitude da terceirização. ${ }^{10}$ De fato, a empresa apresenta estrutura difusa em razão de suas características organizacionais de uso intensivo da informação e comunicação, em formas sempre flexíveis na esके trutura empresarial e na relação de trabalho que $\sim$ se estabelece, na medida em que o empregado é contratado por uma empresa, mas presta serviços para outra (Bridi; Machado; Portela, 2017).

ก ${ }^{10}$ Em alguns dos processos analisados, pode se identificar . um verdadeiro "quebra cabeça" das prestações de serviços; $\rightarrow$ por exemplo, um "empregado da Atento que presta serviço

ธิ para a Mobile, e esta, por sua vez, tem contrato com a Vivo,

西 e o empregado consegue ter reconhecido o vínculo com a

Vivo; empregado da Atento que presta serviço para empre-

$\approx$ sa $\mathrm{x}$, depois se torna empregado de outra empresa que tam-

×ém presta serviço para empresa x e continua exercendo a

mesma função" (Bridi; Machado; Portela, 2017).

${ }^{11}$ Em 2014, por exemplo, entre os seus principais clientes figuravam: Zurich, Motorola, Bradescon, Samsung, Nestlé, Telefônica, L’Oréal, Whirlpool, Vivo, HSBC, Santander, Carrefour, McDonald's, Fiat, Nikon e Natura. bém pelas condições de trabalho.

Outro dado, a ser considerado, nos últimos anos, é sua reorganização espacial. Diversas unidades foram abertas no interior de São Paulo e em cidades nordestinas (geralmente no interior, mas também em capitais), como forma de rebaixamento de custos. Empresas intensas na utilização da força de trabalho passaram a ser disputadas por governos de estado e prefeituras, que fornecem incentivos fiscais e infraestrutura para sua implantação (Moraes, 2018). ${ }^{12}$

\section{AS OCUPAÇÕES "PLATAFORMA"}

Uma das características presentes no trabalho criativo é o compartilhamento e a colaboração existentes em sua elaboração. Assim, entre os desenvolvedores de softwares, aplicativos e jogos digitais, é relativamente comum o compartilhamento de softwares de código aberto como o Mozilla, na resolução em rede de problemas, compartilhamento de informações, ao lado da tendência de fechamento de códigos e utilização privada do que foi compartilhado. Do mesmo modo, podemos nos referir ao trabalho intelectual de forma geral, que passa a ser entendido como apropriação coletiva do conhecimento e sua elaboração, podendo ser coletiva ou individual, do trabalho artístico, entre outros.

O caráter criativo dessas atividades e o engajamento subjetivo de parte significativa de seus trabalhadores têm consequências nem sempre positivas, como a subordinação da vida pessoal ao trabalho e a eliminação da separação entre vida e trabalho, como já vimos.

Temos, no desenvolvimento de jogos (a gamificação) em alguns aplicativos, o envolvimento de milhões de pessoas que contribuem para sua efetivação, experimentando e sugerindo alterações. Trabalho gratuito incorporado por ${ }^{12}$ Estudando call center na Paraíba, Moraes(2018) destaca
uma rotatividade menor que a de outras regiões, decor-
rente da ausência de alternativas de emprego para uma
população jovem escolarizada. 
startups e empresas de tamanhos variáveis. Trata-se do crowd sourcing, isto é a transferência de trabalho das empresas para os usuários navegantes da web. ${ }^{13}$ Para alguns autores, é a terceirização levada a seus extremos (Abílio, 2017; Scholz, 2016). Esse compartilhamento torna-se atividade econômica, funcionando na lógica das visualizações que determinam seu alcance e sucesso. É o caso tanto do Facebook quanto do Youtube, em que youtubers, bloggers e outras atividades progressivamente se profissionalizam.

A partir do desenvolvimento de aplicativos, encontram-se todos os tipos de empresas virtuais que funcionam dentro da chamada economia do compartilhamento. Essa economia coloca em contato demandantes de serviços, como, por exemplo, caronas, carros, espaços para alugar, entregas variadas, e que permitem ganhar dinheiro. A empresa virtual disponibiliza o app a partir de uma taxa determinada e, a partir daí, junta o prestador de serviço com o demandante desse mesmo serviço.

A "uberização" é a situação típica ideal dessa economia de plataforma. Na uberização, o trabalhador é um empreendedor de si, vinculado e subordinado a um app que liga prestadores de serviço a consumidores, intermediados por uma empresa que fica com uma porcentagem do apurado. Trata-se de uma atividade geralmente feita por jovens, como bico, na chamada gig economy, substituta inglesa do "bico" ou da viração.

O conceito de "uberização" para nomear as condições de trabalho flexíveis, desprotegidas, que nublam a relação de emprego, na medida em que se definem como plataforma que disponibiliza uma relação entre motoristas (proprietários de carro) e clientes (passageiros), emerge a partir da UBER, uma empresa criada em 2010 e que se define como de tecnologia e não de transporte. Trata-se de uma indeterminação estratégica para a empresa, uma vez que ela possibilita disfarçar a relação de em-

${ }^{13} \mathrm{O}$ termo é de definição imprecisa, indo de trabalho colaborativo à externalização aberta on-line, incorporando uma série de atividades e ocupações, assim como formas de remuneração (HUWS, 2015). prego. De acordo com a UBER,,$^{14}$ em novembro de 2018, ela já estava presente em 600 cidades no mundo e em mais de 100 (cem) cidades no Brasil. O número de funcionários é de 20.000, entendendo-se como trabalhadores diretos da UBER; mas os motoristas considerados "parceiros" giram em torno de 3 milhões no mundo e mais de 600 mil no Brasil, segundo dados de 2018. Se esses motoristas tivessem uma relação de emprego tipicamente fordista, digamos, estaríamos diante de uma das maiores empregadoras do mundo.

Tabela 2 - UBER: mão de obra e usuários no mundo e no Brasil. 2018

\begin{tabular}{l|c|c}
\hline & No mundo & No Brasil \\
\hline $\begin{array}{l}\text { Funcionários da } \\
\text { UBER/mundo }\end{array}$ & 20.000 & \\
\hline $\begin{array}{l}\mathrm{N}^{\circ} \text { de motoristas } \\
\text { "parceiros }\end{array}$ & $3.000 .000,00$ & 600.000 \\
\hline Usuários & $\begin{array}{c}+ \text { de } 75 \\
\text { milhões }\end{array}$ & $\begin{array}{c}+ \text { de } 22 \\
\text { milhões }\end{array}$ \\
\hline
\end{tabular}

Fonte: Adaptado UBER. Disponível em https://www.uber.com/pt-BR/newsroom/fatos-e-dados-sobre-uber/. Acesso em: 16.02.2019.

Considerando que essa empresa inicia suas atividades no Brasil em 2014, o que se verifica em termos de ocupação da mão de obra é estrondoso. O número de motoristas cresce vertiginosamente, guardando forte relação com o desemprego no país. Somente no ano de 2016, segundo dados da UBER, o número de motoristas saltou de 50 mil para 500 mil, com cerca de 17 milhões de usuários no país. Em 2018, o número de motoristas já tinha saltado de 500 mil do ano anterior para 600 mil. Ou seja, todos os dias, trabalhadores desempregados que não conseguem ocupação fixa tendem a entrar para o segmento.

A concorrência da UBER tem desestruturado os serviços regulares de taxi e provocado revolta e mobilizações entre os taxistas, uma categoria de trabalhadores que, até pouco tempo, mantinha grande controle sobre seus mercados de trabalho através de compra de licenças, negociação dessas licenças com as prefeituras, determinando monopólios de atendimento a

${ }^{14}$ Ver em <https://www.uber.com/pt-BR/newsroom/fatos-e-dados-sobre-uber/>. Acesso em: 16.02.2019. 
determinados espaços das cidades, o acesso a pontos etc. Tal situação vem encolhendo com a concorrência das plataformas incidindo diretamente sobre os ganhos diários desses trabalhadores e no preço dessas licenças.

A desestruturação dos mercados tradicionais também acontece em aplicativos de distribuição de comidas e outros serviços em diversas cidades do mundo, que contratam motoqueiros e distribuidores motorizados em geral (Abílio, 2017; Scholz, 2016). Em comum, a ausência de limites nas jornadas de trabalho, e o ganho apenas quando trabalham.

A prefeitura de Ribeirão Preto, no interior de São Paulo, propôs um projeto de lei para utilização de professores substitutos na rede municipal de ensino através de um aplicativo. Eles não teriam nenhum vínculo com a prefeitura e seriam mobilizados quando da falta de professores. Teriam 30 minutos para responder se aceitam e 1 (uma) hora para aparecer na escola. Apesar das críticas das associações docentes que tentavam brecar o projeto, a secretaria da educação daquele município enaltecia as vantagens do novo sistema que resolveria o problema das faltas constantes dos docentes (FSP 23/07/2017). Tal situação já está presente em escolas privadas de ensino não presencial, principalmente de idiomas, nas quais profes$\stackrel{\rightarrow}{\vec{I}}$ sores cadastrados ficam à disposição on-line para a resolução de problemas dos alunos.

Projeto similar foi apresentado na Inglaterra pelo ministro da saúde, para a utilização de enfermeiros e enfermeiras através de contratos de plataforma, assim como tentativas de consultas médicas através de aplicativos.

Com um apelo inicial alternativo, o proeto termina por se caracterizar como uma terceirização precarizante. Mas tem causado reações e mesmo greves na Inglaterra e na Itália, provocando igualmente novas formas de organização dos trabalhadores que utilizam esses mesmos aplicativos para resistir à exploração Abílio, 2017). Da mesma forma que a plataforma elimina a relação direta entre patrão e empregado, ela favorece o contato entre os trabalhadores pelos dispositivos informacionais que caracterizam o acesso à plataforma: a internet. Isso tem possibilitado movimentos contra as plataformas e conquistas acerca de formas de regulamentação.

\section{A REFORMA TRABALHISTA E AS CONFIGURAÇÕES DO TRABALHO MEDIADAS PELA TIC}

Em 13 de julho de 2017, o governo de Michel Temer, que ocupou a presidência após o impeachment de Dilma Rousseff, sancionou a Lei 13.467/2017, promovendo a mais expressiva mudança na legislação do trabalho brasileira. Foram inúmeras alterações que tendem a legalizar e institucionalizar as diversas modalidades flexíveis de trabalho e emprego e dificultar o acesso dos trabalhadores à Justiça do Trabalho. ${ }^{15}$

Podemos dizer que se abriu, então, uma nova agenda de pesquisa sobre trabalho (sociologia do trabalho, economia do trabalho, entre outras). Entre os desafios dessa nova agenda, está a mira para o pool das novas ocupações e das velhas ocupações que foram reconfiguradas pelas tecnologias. As tecnologias de informação e comunicação (TICs), de fato, não apenas permitiram novos negócios e uma diversidade de arranjos de empresas, como também alteraram o trabalho, as condições de realização do trabalho, as jornadas, os espaços onde o trabalho pode ser realizado, assim como a própria noção de trabalho. Reconfigurou-se o trabalho em domicílio que, mesmo revestido da modernidade das ferramentas tecnológicas, apresenta uma faceta tradicional, na qual trabalho e vida privada se confundem, além das longas jornadas mescladas pelo trabalho doméstico. Essa convivência do moderno e do tradicional se manifesta nas relações de trabalho e emprego sem proteção alguma aos trabalhadores, que não se

${ }^{15}$ Cada vez mais faz sentido falar em trabalho e não emprego, visto que os empregos protegidos, regulados, tendem a ser reduzidos. 
deve à tecnologia em si, mas aos imperativos da busca do capital pela lucratividade.

Dentre as modalidades "novas" de organização do trabalho, o teletrabalho compreende aquelas atividades que podem ser realizadas fora do chão da empresa (espaço físico), e podem ser organizadas em rede, o que é possibilitado pelas tecnologias de informação usadas de forma intensiva. O teletrabalho "é uma forma de trabalho efetuado fora da empresa central e do centro produtivo e que implica uma nova tecnologia, que permite a separação e facilita a comunicação" (Machado, 2009, p. 131). Essa modalidade de trabalho foi regulada pelo Artigo 75 da Reforma Trabalhista, que define as suas condições:

Art. 75-A. A prestação de serviços pelo empregado em regime de teletrabalho observará o disposto neste Capítulo.

Art. 75-B. Considera-se teletrabalho a prestação de serviços preponderantemente fora das dependências do empregador, com a utilização de tecnologias de informação e de comunicação que, por sua natureza, não se constituam como trabalho externo.

Parágrafo único. O comparecimento às dependências do empregador para a realização de atividades específicas que exijam a presença do empregado no estabelecimento não descaracteriza o regime de teletrabalho.

Art. 75-C. A prestação de serviços na modalidade de teletrabalho deverá constar expressamente do contrato individual de trabalho, que especificará as atividades que serão realizadas pelo empregado.

$\S 1^{\circ}$ Poderá ser realizada a alteração entre regime presencial e de teletrabalho desde que haja mútuo acordo entre as partes, registrado em aditivo contratual.

$\S 2^{\circ}$ Poderá ser realizada a alteração do regime de teletrabalho para o presencial por determinação do empregador, garantido prazo de transição mínimo de quinze dias, com correspondente registro em aditivo contratual. (Brasil, 2017)

As condições podem ser alteradas a qualquer momento, desde que acordadas pelo empregado e o empregador, sem, contudo, assegurar a assistência do sindicato ao trabalhador.

Trata-se de uma legislação que, segundo o Ministério Público do Trabalho (MPT), em sua nota técnica $n^{0} 08 / 2017$, possibilita a transferência de parte dos custos e dos riscos da atividade econômica ao empregado. Isso é incompatível com os direitos estabelecidos na Constituição de 1988, visto que violam os direitos fundamentais previstos no art. 72, incisos IV, VI e VII da Constituição.

A transferência dos riscos para os trabalhadores, apontada pelo MPT para os casos dos teletrabalhadores, se generaliza, de fato, para as novas ocupações, como, por exemplo, os motoristas de UBER e de outras plataformas, e se estende para outras categorias de trabalhadores. Além da transferência de riscos e custos para os trabalhadores eufemisticamente chamados de "parceiros", "colaboradores", e mesmo "empreendedores", a reforma trabalhista assegura que essas empresas possam dispor de uma mão de obra sem limites de jornada de trabalho, sem direitos a férias e outras proteções.

Trata-se de condições que não têm relação, em si, com as tecnologias. As tecnologias apresentam o potencial de facilitar o trabalho, mas, em uma sociedade neoliberal, as novas ocupações são desreguladas pelo Estado e pelo mercado com vistas à mera redução de custos do trabalho.

Longe de esgotar o debate, destacamos ainda que a reforma trabalhista, no Brasil, aprovou duas leis que regulam a intermediação de mão de obra, passando a autorizar sua adoção de modo irrestrito nas atividades-fim da empresa, antes vedado pela jurisprudência. A Lei n. 13.429/17 regulamentou a possibilidade de intermediação de mão de obra via contratação de serviço temporário, que era limitada pela lei anterior, n. 6.019/74, pelo período de três meses; e uma segunda lei, publicada em 13 de julho de 2017 (Lei 13.476/17), que passou a permitir a terceirização em todas as atividades-fim da empresa (Bridi; Machado; Portela, 2017). Com essas mudanças, a legislação favorece a desproteção dos trabalhadores de novas ocupações, e fornece um leque de possibilidades flexíveis e precárias de contratação de trabalho, de modo que a precariedade passa a ser um traço característico dessas novas ocupações. 


\section{CONCLUSÃO}

Ao analisar o futuro do trabalho na sociedade resultante da quarta revolução industrial da internet das coisas, que Rifkin (2016) vai chamar de "sociedade com custo marginal zero", ele é contido e mesmo pessimista. A tendência, segundo ele, é a eliminação crescente de postos de trabalho em categorias até agora pouco ameaçadas, como caminhoneiros e trabalhadores de confecções. A automação e a robótica eliminariam diversos cargos na prestação de serviços, e mesmo os trabalhadores do conhecimento poderão ser dispensados pela utilização da mesma tecnologia que desenvolve TI. Megadados e algoritmos reduziriam o custo marginal da mão de obra, e haveria uma desvinculação entre produtividade e emprego. E, sem empregos, quem compraria as mercadorias? Velha questão, já situada e sempre retomada no debate sobre as crises cíclicas do capitalismo.

Mas, enquanto o apocalipse não chega, assistimos ao surgimento de novas ocupações vinculadas a novas tecnologias, exigindo, de um lado, profissionais altamente qualificados e, de outro, trabalhadores especializados. Como trabalho criativo, os trabalhadores de software utilizam seu conhecimento para produzir pro-

If gramas, aplicativos e jogos, os quais, por sua vez, lhes criam problemas, no sentido de ser um trabalho sem fim, no qual jornadas se borram, e a vida pessoal é colonizada pelo trabalho: trabalha-se o tempo todo, mesmo quando se acha que se trata de uma diversão, ao jogar ou experimentar apps, softwares novos etc. Mesmo dominando os processos, o trabalhador é obrigado a vender sua força de trabalho, e o mercai do determina seu preço. Há maior autonomia em algumas das atividades, sem dúvida, mas o trabalhador continua subordinado. A precariedade se encontra nos processos de trabalho, no tempo necessário para sua produção e nas modalidades de contratação.

No trabalho em hardware e em call center, a padronização é quase total, com trabalho altamente taylorizado. Nesses, como nos de software, a precariedade encontra-se menos nas relações de trabalho e mais nas condições de trabalho extenuantes, nervosas, emocionais. Ou seja, o trabalho formalizado atenua, mas não elimina a precariedade.

No caso dos empregos de plataforma, ou bicos, a situação é variável podendo existir desde ocupações, na internet, que necessita de likes para ganhar dinheiro (como youtubers e bloggers), até a prestação de serviços de entrega, taxis etc. Não existem vínculos ou qualquer estabilidade. É a lógica do empreendedor de si mesmo, sem limites de jornada ou qualquer outra forma de controle do tempo despendido. Direitos, então, nem pensar. E o tecnoliberalismo pleno, no qual não existe qualquer formalização ou limites das jornadas, e o trabalhador não tem acesso ao patrão, que funciona como intermediário na prestação de serviços.

Embora com qualificações distintas, algumas características comuns juntam os trabalhadores de software, call centers e de plataforma. A alta escolaridade, maior no primeiro caso, mas ainda alta para os padrões brasileiros das outras duas (call centers e plataforma) e a precariedade inerente à organização da produção.

Resistência? Há várias possibilidades que questionam as formas sindicais tradicionais. As redes virtuais, da mesma forma que possibilitam acesso à informação sobre empregos, permitem também a discussão de direitos e a organização de movimentos contra empresas. Em termos de representatividade sindical, vários sindicatos disputam as categorias, embora sem grande entrada ou influência em suas bases. O que não significa que os trabalhadores estejam desinformados. As redes sociais funcionam igualmente como fonte de atualização salarial no mercado de trabalho, como formas de regulamentação, e de informação sobre direitos. Têm a potencialidade de virem a se constituir numa arma poderosa para resistir à exploração sem fim vislumbrada pelos novos rumos de uma sociedade informa- 
tizada, na qual a tecnologia, por um lado, facilita a vida e, por outro, a precariza.

Recebido para publicação em 20 de abril de 2019 Aceito em 16 de maio de 2019

\section{REFERÊNCIAS}

ABÍLIO, L. C. Uberização do trabalho: subsunção real da viração. Disponível em http://passapalavra. info/2017/02/110685. Acesso em: 15.05.2017.

ANTUNES, R; BRAGA, R. Infoproletários: degradação real do trabalho virtual. São Paulo: Boitempo, 2009.

BENNER, C. Improvisational Reform: building collective voice and security in Silicon Valley. In: KUDVA, N.; BENERIA, L. (Eds.) Rethinking informalization: poverty, precarious jobs and social protection. Ithaca: Cornell University Open Acess Repository, 2005.

BRASIL. Lei $\mathrm{n}^{\circ}$ 13.467, de 13 de julho de 2017. Disponível em http://www.planalto.gov.br/ccivil_03/_ato20152018/2017/lei/l13467.htm. Acesso em: 14.02.2019.

BRAVERMAN, H. Trabalho e capital monopolista. A degradação do trabalho no século XX. $3^{\mathrm{a}}$ edição. Rio de Janeiro: Editora Guanabara, 1974.

BRIDI, M. A. O setor de Tecnologia da Informação: o que há de novo no horizonte do trabalho? Política e Trabalho, João Pessoa, n. 41, p. 277-304, out. de 2014.

BRIDI, M. A.; BRAUNERT, M. O trabalho na indústria de software: a flexibilidade como padrão das formas de contratação. Caderno CRH, Salvador, v. 28, n. 73. p. 199213, jan./abr. 2015.

BRIDI, M. A.; MACHADO, S.; PORTELA, G. Terceirização, cadeia produtiva e reconfiguração da noção de empregador: o caso atento. In: XXXXI CONGRESO ALAS. Montevideo-Uruguay, 3-8 dic./ 2017. Disponível em http:// alas2017.easyplanners.info/opc/tl/0521_maria_aparecida. pdf. Acesso em: 16.02.2018.

BROAD, D. The periodic casualization of Work: the informal economy, casual labor, and the Longue Durée. In: TABAK, F.; CRICHLOW, M. A.(Ed.) Informalization: Process and Structure. Baltimore: The Johns Hopkins University Press, 2000.

CASTELLS, M. A galáxia da Internet: reflexões sobre a internet, os negócios e a sociedade. Rio de Janeiro: Zahar, 2003.

CASTELLS, M. A sociedade em rede. São Paulo: Paz e Terra, 1999.

CASTRO, B. As armadilhas da flexibilidade: trabalho e gênero no setor de tecnologia da informação. 1. edição. São Paulo: Annablume, 2016

CORSANI, A. Elementos de uma ruptura: a hipótese do capitalismo cognitivo. In: COCCO, G.; GALVÂ, A. P.; SILVA, G. Capitalismo cognitive: trabalho, redes e inovação. Rio de Janeiro: DP\&A, p.15-32, 2003.

COUTINHO, A. et al. Quadro comparativo - Redação anterior da CLT e redação dada pela Lei n. 13.467/2017. Curitiba: UFPR, 2017. (mimeo).

DIEESE. O processo de terceirização e seus efeitos sobre os trabalhadores no Brasil. Relatório Técnico. Sistema de Acompanhamento de Contratações Coletivas - SACCDIEESE, 2003.

FLECKER, J. Space, place and global digital work. London: Palgrave Macmillan, 2016.
FOLHA DE SÃO PAULO. Número de motoristas do Uber cresce dez vezes em um ano no Brasil. Disponível em https:// www1.folha.uol.com.br/cotidiano/2017/10/1931013numero-de-motoristas-do-uber-cresce-dez-vezes-em-umano-no-brasil.shtml. Acesso em: 08.01.2018.

GUTIÉRREZ, J.G.R. Aprendizaje y resistência en los trabajadores de software. Hermosillo-México-DF: Universidad de Sonora- Plaza y Valdez Editores, 2011.

HUWS, U. Análise sobre o futuro do trabalho: bolsas de trabalho on-line ou externalização aberta «crowdsourcing»: implicações para a segurança e saúde no trabalho. Documento de Reflexão, Bilbao, EU-OSHA, 2015.

KUMAR, K. Da sociedade pós-industrial à pós-moderna. Novas teorias sobre o mundo contemporâneo. Rio de Janeiro: Jorge Zahar Ed., 1997.

KREIN, J. D. Reforma Trabalhista FHC: Efetividade e Consequências. In: VII ENCONTRO NACIONAL DA ABET. São Paulo: ABET, 2001.

LIMA, J. C. Uma sociologia do trabalho digital: desafios

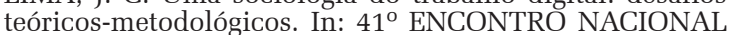
DA ANPOCS. Caxambu, out. 2017.

LIMA, J. C.; BRIDI, M. A. O trabalho digital e os trabalhadores. In: BRIDI, M. A.; LIMA, J. (Orgs.) Flexíveis, virtuais e precários? Os trabalhadores em tecnologia da informação: Editora da UFPR: Curitiba, 2018.

LIMA, J. C.; OLIVEIRA, D. R. Trabalhadores digitais: as novas ocupações no trabalho informacional. Sociedade e Estado, Brasília, v. 32, n. 1, jan./abr. 2017.

LUPTON, D. Digital Sociology. London-New York: Routledge, 2015.

MACHADO, S. A noção de subordinação jurídica: uma perspectiva reconstrutiva, São Paulo: LTr, 2009.

MARRES, N. Digital sociology: the reinveition of social research. Cambridge(UK): Polity Press, 2017.

MAYER-AHUJA, N.; WOLF, H. Beyond the hype. Working in the German internet industry. Critical Sociology, v. 33, p.73-99, 2007.

MIGUEZ, P.; LIMA, J. C. El trabajo cognitivo en el capitalismo contemporáneo: el surgimiento y la evolución del sector software en Argentina y Brasil. Cuadernos Del CENDES, Venezuela, v. 33, p. 35-65, 2016.

MINISTÉRIO PÚBLICO DO TRABALHO. Nota técnica $\mathrm{n}^{\mathrm{o}} 8$, de 16 de junho de 2017. Disponível em http://portal.mpt.mp.br/wps/wcm/connect/ portal_mpt/ce4b9848-f7e4-4737-8d81-6b3c6470e4ad/ Nota + t\% C 3\% A 9 c n i ca + n\% C $2 \%$ B A + 8.2017. pdf?MOD=AJPERES\&CVID=lPCHY69. Acesso em: 15.02.2019.

MISKOLCI, R. Sociologia digital: notas sobre pesquisa na era da conectividade. Contemporânea, Salvador, v. 6, n. 2 p. 275-297, jul./dez. 2016.

MORAES, A.C.N. Trabalhadores de Call Centers: trabalho precário e resistências na Paraíba. 2018. Tese (Doutorado em Sociologia) - UFPB, João Pessoa.

MOULIER BOUTANG, Y. Cognitive Capitalism. Cambridge (UK): Polity Press, 2011.

NASCIMENTO, L. F. A Sociologia digital: um desafio para o século XXI. Sociologias, Porto Alegre, ano 18, n. 41 p. 216-241, jan./abr. 2016.

OLIVEIRA, D.R. Do fim do trabalho ao trabalho sem fim: o trabalho e a vida dos trabalhadores digitais em Home Office. 2017. Tese (Doutorado em Sociologia)- UFSCar, São Carlos.

ORTON-JOHNSON, K.; PRIOR, N. (Eds). Digital sociology: critical perspectives. Basingstoke: Palgrave Macmillian, 2013. 
PAULANI, L. M. Acumulação e rentismo: resgatando a teoria da renda de Marx para pensar o capitalismo contemporâneo. Revista de Economia Política, São Paulo, v. 36, n. 3, p. 514-535, jul./set. 2016.

RIFKIN, J. Sociedade com custo marginal zero. A internet das coisas, os bens comuns colaborativos e a eclipse do capitalismo. São Paulo: M. Books, 2016.

ROSELINO, J. E. Panorama da indústria brasileira de software: considerações sobre a política industrial. (Org.) DE NEGRI, J. A.; EKUBBTA, L. C. Estrutura e dinâmica no setor de serviços no Brasil. Brasília: IPEA, 2006.

SADIN, É. La silicolonisation du monde. Le irresistible expansion du libéralisme numérique. Paris: Éditions L'Échappée, 2016.

SCHOLZ, T. Cooperativismo de plataforma: contestando a economia do compartilhamento cooperativa. São Paulo: Fundação Rosa Luxemburgo; Editora Elefante; Autonomia Literária, 2016.
TRABALHO DIGITAL E EMPREGO: a reforma trabalhista ...

SLEE, T. Uberização: a nova onda do trabalho precarizado. São Paulo: Editora Elefante, 2017.

SOFTEX. Software e Serviços de TI: a indústria brasileira em perspectiva. Campinas: Observatório Softex, 2012. n. 22.

TAINTURIER, B.; DUEZ, E. Décoder les développeurs. Enquete sur une profession à l'avant-garde. Paris: Eyrolles, 2017.

URRY, J. Sociology beyond societies: mobilities for the twenty-first century. London and New York: Routledge, 2000 .

UBER. Disponível em https://www.uber.com/pt-BR/ newsroom/fatos-e-dados-sobre-uber/. Acesso em: 16.02.2019.

WYNN, J. R. Digital sociology: emergent technologies in the field and the classroom. Sociol Forum, v. 24, n. 2, p. 448-456, 1 jun. 2009.

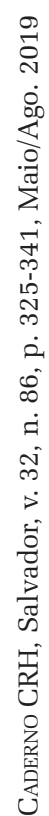

340 
DIGITAL WORK AND EMPLOYMENT: the labor reform and the deepening of precariousness

\author{
Jacob Carlos Lima \\ Maria Aparecida Bridi
}

This article aims to analyze the changes in Labor in terms of it's flexibility of relations, technology and emerging occupations from new Technologies of Information and Communication (TICs). Among the analyzed activities are the Software developers, hardware assemblers in computing factories, outsourced call center attendants and digital platform workers. One of the issues analyzed, although preliminarily, is in wich measure the change in Labor Law, ocurred in 2017 in Brazil, favored the "Uberization"of Work. By analizing these activities and it's kinds of contract, we concluded that precariousness is an element of the aforementioned occupations, which were originated in a context of flexibility and technological innovations, made possible by the Internet, mixing time and space, shuffling issues that are part of the own value of labor, material and imaterial and in the own concept of Enterprise. One of the most contradictory facets of the so called flexible capitalisme consists in the transfer of risk of economic activity to the workers.

KEY WORDS: Information and Communication Technologies. Uberization. Labor reform. Technoliberalism
LE TRAVAIL DIGITAL ET L'EMPLOI: la reforme du travail et l'approfondissement des precarites

\author{
Jacob Carlos Lima \\ Maria Aparecida Bridi
}

Cet article cherche à analyser les changements dans le monde du travail surtout à propos de la flexibilisation des relations et les surgissement et des nouveaux postes de travail parvenus des "Technologies de l'Information et de la Communication (TIC)". Parmi les occupations analysées se trouvent les développeurs de software, les assembleurs de matériel de hardware, les télévendeurs et les travailleurs des plate-formes númeriques. On a pu analyser, de façon preliminaire, le changement du réglement au travail au Brésil, que a eu lieu en 2017, bien que leur influence sur "l'uberisation" du travail dans ce pays. Après avoir étudié les tâches et les contrats du travail, on est arrivés à la conclusion selon laquelle les précarités au travail sont la réalitée des nouveaux métiers, crées par l'espace de l'innovation tecnologique, où l'on mélange les notions de temps et l'espace, de matériel et l'immatériel, de la valeur du travail et de l' entreprise. Finalment, on envisage l'une des plus sevères contradictions $\mathrm{du}$ "capitalisme fléxible”, à savoir, le dêpot des risques de l'activité économique sur les travailleurs.

Mots-CLÉs: Des technologies de l'information et de la communication. L'uberisation. Réforme du travail. Technolibéralisme.

Jacob Carlos Lima - Doutor em Sociologia pela Universidade de São Paulo. Professor do Departamento de Sociologia da Universidade Federal de São Carlos. Coordena o Laboratório de Estudos sobre Trabalho, Profissões e Mobilidades (LEST-UFSCar). Possui diversas publicações na área de Sociologia do Trabalho, em temáticas como trabalho informal, trabalho digital, cooperativas de trabalho e cultura do trabalho.

Maria Aparecida Bridi - Doutora em Sociologia pela Universidade Federal do Paraná. Professora do Departamento de Sociologia da Universidade Federal do Paraná. Coordena o Grupo de Estudos Trabalho e Sociedade (GETS). Publicou livros, capítulos de livros e periódicos científicos na área de Sociologia e Sociologia do Trabalho, sobre as configurações do trabalho, trabalho informacional, indústria automobilística e metalúrgicos, ação coletiva e sindicalismo. 
